\title{
Decision Support for Sustainable Urban Renewal: A Multi- scale Model
}

DOI:

10.1016/j.landusepol.2017.09.019

\section{Document Version}

Accepted author manuscript

Link to publication record in Manchester Research Explorer

\section{Citation for published version (APA):}

Zheng, W., Shen, G. Q. P., Wang, H., Hong, J., \& Li, Z. (2017). Decision Support for Sustainable Urban Renewal: A Multi-scale Model. Land Use Policy, 69, 361-371. https://doi.org/10.1016/j.landusepol.2017.09.019

\section{Published in:}

Land Use Policy

\section{Citing this paper}

Please note that where the full-text provided on Manchester Research Explorer is the Author Accepted Manuscript or Proof version this may differ from the final Published version. If citing, it is advised that you check and use the publisher's definitive version.

\section{General rights}

Copyright and moral rights for the publications made accessible in the Research Explorer are retained by the authors and/or other copyright owners and it is a condition of accessing publications that users recognise and abide by the legal requirements associated with these rights.

\section{Takedown policy}

If you believe that this document breaches copyright please refer to the University of Manchester's Takedown Procedures [http://man.ac.uk/04Y6Bo] or contact uml.scholarlycommunications@manchester.ac.uk providing relevant details, so we can investigate your claim.

\section{OPEN ACCESS}




\title{
Decision Support for Sustainable Urban Renewal: A Multi-scale Model
}

Author details:

1. Wei Zheng, helen.zheng@manchester.ac.uk, School of Environment, Education \& Development (Planning), The University of Manchester, Manchester, U.K.

2. Geoffrey Qiping Shen, geoffrey.shen@polyu.edu.hk, Department of Building and Real Estate, The Hong Kong Polytechnic University, Kowloon, Hong Kong

3. Hao Wang, holy.wong@,connect.polyu.hk, School of Management Science and Engineering, Central University of Finance and Economics, Beijing, P. R. China.

4. Jingke Hong, hongjingke@gmail.com, School of Construction Management and Real Estate, Chongqing University, Chongqing, P.R. China

5. Zhengdao Li, clydelee718@gmail.com, College of Civil Engineering, Shenzhen University, P.R. China

\begin{abstract}
Developed cities are troubled by various challenges, including urban dilapidation, environmental pollution, traffic congestion, lack of facility provision, and economic decline. Urban renewal, as an important agenda in most countries, holds the aim of addressing these urban problems. With the inherent complexity of urban renewal, renewal initiatives do not always follow a sustainable path, which has obtained much criticism from both academia and the public. Therefore, an informative decision-making process would contribute to better renewal outcomes. Previous research has mainly focused on one aspect of urban renewal, in which a comprehensive perspective is lacking. The multi-scale feature of urban renewal initiatives also adds complexity and uncertainty to decision-making. Therefore, this paper proposes a multi-scale model that supports decision-making on realizing sustainable urban renewal. Three sub-modules and a supporting database are included in the model. City, district, and neighborhood scales are the foci of the three sub-modules. Both temporal and spatial data are included in the database. Through experimental study and expert interview, the effectiveness of this model is validated.
\end{abstract}

\section{Introduction}

Cities, especially developed cities, are constantly facing various challenges such as urban decay, environmental deterioration, lack of infrastructure, social problems, and economic decline. Urban renewal/regeneration has therefore become part of the research agenda because it has aims that include clearing slums (Zipp, 2012), solving the urban decay issue (Chan and Lee, 2008a; Larsen and Hansen, 2008), improving urban economy (Musterd and Ostendorf, 2008), 
rectifying social problems (Murgante et al., 2012), and enhancing a city's reputation (Kleinhans, 2004). However, urban renewal initiatives sometimes have not realized their objectives, with some even receiving criticism such as, promoting a source of social exclusion, leading to loss of community identity and only considering profit. These comments implicate the need for better decision-making on and implementation of urban renewal.

Complexity is inherently rooted in urban renewal initiatives, in which different issues and players are involved (Zheng et al., 2014), as well as multiple solutions being provided (Mayer et al., 2005). By adding to this complexity, the urban environment involves different spatial scales such as city, district, neighborhood, and building blocks. This inherent complexity indicates that informed decision-making is crucial for successful urban renewal initiatives. To improve decision-making and implementation for urban renewal, a considerable number of studies have been conducted. Land use, as an essential issue to be addressed in urban renewal, has been explored by many researchers (e.g. Zheng et al., 2015; Wang et al., 2014; Wang et al., 2013). The popularity of the sustainability concept also stimulates much research on the integration of sustainability into urban renewal initiatives (e.g. Lee and Chan, 2010; Colantonio et al., 2009; Chan and Lee, 2008a; Chan and Lee, 2008b; Lee and Chan, 2008; Hemphill et al., 2004a; Hemphill et al., 2004b). Other research focuses on the following issues, but is not limited to, housing (e.g. Zheng et al., 2015b; Winston, 2010), provision of public facilities (e.g. Brown and Barber, 2012; Burrage, 2011) and also stakeholder relationships (e.g. Ruming, 2010; Van Bortel and Elsinga, 2007) in urban renewal actions.

However, a multi-scale perspective, which is one important aspect in the complexity of urban renewal decision-making, has been ignored in previous research. Initiatives at different scales involve different issues and problems. At city scale, relevant policies for urban renewal/regeneration are proposed. In most cases, district, neighborhood, and building scales are at implementation levels. For example, the Netherlands has had a policy, called the "Big Cities Policy", since 1994, and specific policy actions are conducted at neighborhood levels to attract better-off residents, create opportunities, and improve neighborhood restructuring (Musterd and Ostendorf, 2008). Sometimes, if urban renewal initiative is implemented at the building scale, it can only address the physical improvement of that specific building, but may lead to inharmonious relationships with the surrounding area, such as "pencil development" in Hong Kong. A multi-scale perspective of decision-making in urban renewal can contribute to proposing more comprehensive and sustainable policies and actions. Therefore, the current research is to propose a multi-scale model to support urban renewal decision-making. Hong Kong, with its multiple urban problems (e.g. urban decay, land shortage, and pollution), is employed as the case study city to develop three sub-modules and the supporting database. Section 2 reviews research on decision support for urban renewal. Details of model development are introduced in Section 3. Section 4 presents how the proposed model was validated. Section 5 concludes the paper. 


\section{Decision Support for Urban Renewal}

Urban renewal initiatives are beset by complexity (Zheng et al., 2014; Mayer et al., 2005). Urban renewal requires addressing the urban system and the stakeholder-involved social system (Zheng et al., 2014). By adding to these two dimensions, it also involves the technological complexity of potential solutions (Mayer et al., 2005). Considering that various issues, stakeholders, and solutions require balance, decision support is necessary for realizing sustainable urban renewal. Studies have been conducted to explore how to improve urban renewal decision-making.

Some studies only focus on decision support on one critical issue in urban renewal initiatives. For example, Wang et al. (2014) developed a GIS-based framework to support land use planning in urban renewal with three modules of a land information database, planning/policy control mechanism, and land use suitability analysis. Housing, as an essential issue in renewal, has attracted much attention. Housing rehabilitation and redevelopment has been compared with a focus on economic feasibility by Schaaf (1969). These two strategies for housing improvement, both of which hold various advantages and disadvantages, have been widely discussed by researchers (e.g. Yau and Chan, 2008; Ho et al., 2012). To obtain a better understanding of building conditions, the Dilapidation Index in Hong Kong was proposed to assess the potential of urban renewal projects in decision-making (Ho et al., 2011).

The sustainability concept is widely applied in a large number of studies to conduct decision support. An indicator-based approach, with its sustainability indicators, was conceptualized and developed by using a case study to measure urban regeneration performance (Hemphill et al., 2004a; Hemphill et al., 2004b). In the Budapest region, sustainability of property development in urban regeneration was evaluated on physical, social and economic aspects (Kauko, 2012). Peng et al. (2015) integrates a set of sustainability indicators into their proposed model to measure sustainability of urban regeneration. Another indicator-based system, entitled SIPRIUS, was developed to assess sustainability in urban renewal, within which the project dynamics of regeneration of disused urban areas were included (Laprise et al., 2015).

Apart from various issues in urban renewal, the complexity of stakeholders also adds difficulties and uncertainties to urban renewal decision-making. When assessing brownfield developments, Williams and Dair (2007) proposed stakeholder identification in land reuse as one essential part in their framework, in which the assessment of sustainability objectives is another important part. The unlisted property fund sector's investment style was studied with the focus on its impact on decision making in urban renewal/regeneration property in the UK (Haran et al., 2008). Nine types of public-private partnership in Dutch urban land use and revitalization projects within the framework of deregulated land markets were evaluated through a comparative study (Nijkamp et al., 2002). 
Scenario analysis can be applied to support decision-making because it can scrutinize future potential plans, evaluate possible effects from policies, and provide valuable references for decision-makers. For example, Boyko et al. (2012) proposed a toolkit entitled Urban Future to assess urban renewal performance with four future scenarios (urban market forces, urban policy reform, urban new sustainability paradigm, and urban fortress world). A structured sustainability assessment of an existing neighborhood and comparison of three possible scenarios (building improvement, densification according to the legal principles, and densification with adaptation of legal bases) were integrated to evaluate an existing neighborhood in Switzerland to support the urban renewal decision-making process (Pérez and Rey, 2013).

Urban renewal initiatives are proposed in multiple scales. At city scale, renewal direction and policies are proposed. At district and neighborhood scales, specific programs can be implemented, because they are small enough to implement detailed plans. Compared with building scale, these two scales can better address issues for the community and even the whole city, because they are large enough to address other issues in urban renewal such as land use, urban design, and facility provision. Previous research mainly focuses on one project or neighborhood. Research from a multi-scale perspective has not been touched. Multi-scale analysis could provide a more comprehensive understanding on urban renewal for better decision-making. Hence, this research will fill this gap.

\section{Model Development}

\subsection{Process and methods}

Several research methods were adopted to develop and validate the proposed model, including literature review, document analysis, expert interview, simulation, case study, and experimental study. The detailed research process is shown in Figure 1. After defining the research problem, relevant theories, previous research findings, and related documents were reviewed in the library research process. Then, the multi-scale model was conceptualized through reviewing literature, analyzing documents and interviewing experts. When developing different submodules, simulation and case study were the main research methods adopted. Various techniques were also used, including system dynamics modelling, conversion of land use and its effect at small scale (CLUE-S) modelling developed by Verburg et al. (2002), Markov chain prediction, indicator-based approach, and spatial analysis in GIS. To validate this multi-scale model, experimental study and expert interview were employed. During the validation stage, feedback was collected, to further enhance the conceptualized model and modify the submodules.

\section{- Please Insert Figure 1 Here -}

\subsection{Conceptualization of model development}


Three sub-modules are included in this model, which are system dynamics (SD) sub-module, land use simulation (LUS) sub-module, and sustainability assessment (SA) sub-module. An overview of these three sub-modules is shown in Figure 2. Three sub-modules involve three different scales (city, district, and neighborhood).

SD sub-module development generally involves four main steps (see Figure 2): (1) defining and describing system; (2) developing model; (3) validating model and (4) conducting scenario analysis. Urban renewal decision-making can be supported from two main aspects: (1) it could explore sub-systems and variables in the urban renewal process, which provides a better and more comprehensive understanding of urban renewal at city scale; (2) it could generally analyze the influence of different strategies (e.g. rehabilitation, revitalization) on realizing urban renewal objectives through different scenarios.

The LUS sub-module provides decision support at district scale, which simulates future land use. Firstly, the main land use types need to be confirmed. Secondly, the driving factors of each land use need to be selected. Based on analysis of past land use change, the driving factors of land use can be determined respectively. Thirdly, parameters in the LUS sub-module are set to simulate historical land use change. Based on comparison of real data and simulated data, the LUS sub-module setting can be adjusted. Afterwards, the adjusted setting could be adopted to simulate future land use and conduct scenario analysis. The results of the LUS sub-module comprise land use probability maps of different land use types and maps of future land use under different scenarios. These maps can present possible land use problems, which could provide decision-makers in urban renewal with some references.

The SA sub-module provides decision-making support at neighborhood scale. In SA, three categories (environmental, social, and economic) are included for sustainability dimension. Building condition is regarded as a single dimension. These indicators are identified through literature review and expert interview. These indicators could be adjusted under different contexts. Through calculating values in the sustainability dimension and the building condition dimension of the entire neighborhood respectively, a four-quadrant, decision-making matrix is adopted to show directions for different neighborhoods. When both sustainability value and building condition value of a neighborhood are high, minimum change to the neighborhood is suggested. When a neighborhood has a high sustainability value but a low building condition value, revitalization through different approaches should be implemented to improve the entire neighborhood. When the sustainability value of neighborhood is low while the building condition value of neighborhood is high, rehabilitation activities are the first choice to address neighborhood problems. When both values are low, redevelopment may be the best approach to addressing neighborhood problems. Based on the proposed matrix, a decision-maker could gain a clear understanding of neighborhood condition. Details of this sub-module can be referred in Zheng et al. (2016).

These three sub-modules are not isolated. SD provides a general direction for urban renewal. 
Under this general direction, LUS can guide on land use issues, including the possible problems and effects of different policies/strategies based on its simulation of future land use. Neighborhood problems can be found, based on SA results, and a specific strategy can be proposed accordingly. By combining LUS and SA, specific strategies and approaches can be raised.

\section{- Please Insert Figure 2 Here -}

\subsection{Supporting database}

To support urban renewal decision-making, crucial information was collected to establish a supporting database. In this database, data at three scales and urban renewal-related information are collected. Through data processing and integration, spatial and temporal databases are established. Their forms are maps, tables, and texts. After processing data, the supporting database was established, containing economic, social, and environmental information. Land use data and building condition data are also included in output layer. There are mainly two steps for establishing this supporting database. Because the current study selected Hong Kong as the case, the steps of developing this database are illustrated by using Hong Kong. ArcGIS software package was adopted to develop the spatial database. Excel tables were used for temporal data storage.

\section{Data collection}

Data at city scale are from statistical tables relating to society, economy, environment, and real estate. Because the focus of this study is Hong Kong, the data are collected from Census and Statistics Department, Urban Renewal Authority, and Building Department in Hong Kong. Data at district scale are from digital topographic map of Hong Kong, Hong Kong land utilization maps (years of 2000, 2003, 2006, and 2009), remote sensing images, governmental documents and property transaction records. These data were collected from the Planning Department, Lands Department, and web of Centamap of Hong Kong. Data at neighborhood scale are also from digital topographic map, current land utilization map, statistical tables at neighborhood scale, and spatial map of buildings, all of which are collected from the Planning Department, Lands Department, Census and Statistics Department, and Building Department.

\section{Data processing}

After collecting the raw data, these data from different sources are processed and integrated in the supporting database. Data at city scale are stored as tables in temporal dimension (from 2001 to 2012). Data at district and neighborhood scales are stored as spatial data, which also include associated attributes. Data processing activities comprise digitalization of land use maps, derivation of different information from digital maps, spatial analysis of some information, and integrate some non-spatial attributes with spatial data.

\section{- Please Insert Figure 3 Here -}


3.4 Results of developing three sub-modules

Hong Kong is selected to develop the sub-modules. Specifically, the entire Hong Kong city is used for developing the SD sub-module (city scale). Yau Tsim Mong (YTM) district in Hong Kong is the case district for conducting the LUS (district scale). Two neighborhood units in YTM are selected to illustrate the SA sub-module (neighborhood scale). Figure 4 shows the case study area at three scales.

\section{- Please Insert Figure 4 Here -}

\section{Results of the SD sub-module}

The SD sub-module was established, based on Hong Kong's practice. The boundary is the urban renewal system in Hong Kong. The time scale of SD is from 2001 to 2024. Vensim software is the modelling environment for developing the SD sub-module. Three pillars (society, economy, and environment) of sustainable development correspond to common objectives of urban renewal (Zheng et al., 2014); urban renewal projects involve many old buildings and their affected society and environment. Therefore, environmental, social, and economic variables were conceptualized and simulated in this sub-module. Figure 5 shows the modeling interface in Vensim. Because another paper by the authors discusses the details of developing $\mathrm{SD}$, they are not presented in this paper.

Through the SD sub-module, the required urban renewal projects in the future were simulated. Required urban renewal projects represent both redevelopment and rehabilitation projects. Apart from a baseline scenario (following historical trend), two other scenarios were set to simulate the change of required urban renewal projects at city scale in the future, which shows different effects of rehabilitation and redevelopment on reducing required urban renewal projects. Scenario 2 is to simulate the trend of the required urban renewal projects when increasing provision of redevelopment projects. The aim of scenario 3 is to explore the effect of increasing provision of rehabilitation projects on reducing required renewal projects. Table 1 presents simulation results under three scenarios. Required urban renewal projects decrease more quickly under scenario 3. The main implication from SD is that rehabilitation can address urban decay more efficiently in the Hong Kong context, which is also a general reference for decision makers. When they attempt to solve the urban decay issue, the first choice should be rehabilitation rather than redevelopment.

\section{- Please Insert Figure 5 Here -}

\section{- Please Insert Table 1 Here -}

\section{Results of the LUS sub-module}

In this study, a developed district in Hong Kong, YTM, is selected for the development of the LUS sub-module. Seven land use types are identified, which are commercial, residential, industrial, open space, institutional and community facilities (G/IC), vacant, and others. The 
driving factors for different land use types were confirmed through analyzing land use change from 2000 to 2009 (see Table 2). Land utilization of 2000 and land utilization of 2009 were used to set and modify sub-module settings. Then, land utilization of 2018 was simulated based on improved sub-module settings. Because the case is only for illustrating the LUS sub-module, only probability maps of different land use types in 2018 are shown in this paper (see Figure 6). More details of how to develop this sub-module can be seen in another paper by the authors (Zheng et al., 2015a).

\section{- Please Insert Table 2 Here - \\ - Please Insert Figure 6 Here -}

\section{SA sub-module}

In this study, neighborhood units A and B were selected to illustrate SA sub-module development. Both neighborhood A and neighborhood B are tertiary planning units adopted by the Planning Department in Hong Kong, for planning purposes. Referring to the land utilization map in LUS, main land use types in both neighborhood units could be obtained. In neighborhood A, seven main land use types could be found. In neighborhood B, residential land use accounts for a large proportion, and commercial area occupies a small part. When conceptualizing SA sub-module, calculation methods, and thresholds of indicators and overall scores of sustainability and building condition are determined for Hong Kong contexts by adopting the literature review and expert interview methods. Due to the limited length of this paper, only the standardized results of neighborhoods A and B are presented in Table 4. The aforementioned four-quadrant decision-making matrix is presented in Figure 7, showing proposed strategies for $\mathrm{A}$ and $\mathrm{B}$.

\section{- Please Insert Table 3 Here - \\ - Please Insert Table 4 Here - \\ - Please Insert Figure 7 Here -}

\section{Integration of three sub-modules}

In terms of the case of Hong Kong, for illustration, a general direction for urban renewal in Hong Kong is that different strategies can be adopted but with prior consideration on urban rehabilitation, since it plays a more effective role in reducing required urban renewal projects. For the neighborhood A unit in YTM, revitalization is suggested since its sustainability value is comparatively low. Considering the results of LUS, open space is found to have lower probability in that neighborhood, which indicates that provision of more open space in revitalization could benefit A. Additionally, outdated industrial buildings in A could be adapted to other uses (e.g. cultural industry). In terms of neighborhood B in YTM, rehabilitation is considered as the first choice to address the current urban decay problem, with its low value of building condition. Through looking into its land use, based on LUS results, more open space provision could also be included in the future renewal because this neighborhood has a large 
proportion of residential land use and a low open space probability in the future, indicating that the residential neighborhood requires more open space.

\section{Model Validation}

To validate the proposed model, experimental study and expert interview are adopted. This section introduces results of expert interviews and experimental study.

\subsection{Expert interview}

Three expert interviews were conducted to collect opinions on the proposed model, after developing sub-modules, by using the Hong Kong case. One expert is currently a professional in URA and senior lecturer in a university in Hong Kong. Another expert is a planner in the Planning Department. A further expert is a well-known professor in the urban planning field in the USA. During interviews, the proposed model was firstly explained to the professionals and then six questions were asked on the effectiveness of the model. The first question asked about the effectiveness of the SD sub-module. The second question collected comments on the LUS sub-module. The third and fourth questions were designed for the SA sub-module. The fifth question explored the usefulness of the overall model for strategic decision-making. The final question collectedother suggestions and comments that were not included in previous questions.

Generally, all experts held positive comments on the model and three sub-modules. They gave some suggestions on further improving this model, such as some terms in SD and SA needing to be changed to avoid confusion. Therefore, the terms shown in this paper and the experimental study have been modified. Another comment is that probability maps of different land use types in LUS should be referred to together, when making decisions.

\subsection{Experimental study}

\section{Purpose of experimental study}

The experimental study aims at testing whether the proposed multi-scale framework can provide decision makers with useful references for urban renewal decision-making and facilitate objective and effective decision-making.

\section{Design of experimental study}

The experimental study compared the effects of using a traditional decision method and applying the proposed decision support model in decision-making. Eighteen graduate students with similar educational backgrounds, such as urban planning, land management and construction management, participated in the experimental study. Some of the participants also have working experience in planning-relevant fields. Additionally, none of them had a prior understanding on the characteristics of the experiment and the contents of this study.

The duration of the experiment (in a form of workshop) was around one-and-a-half hours. These 
participants were divided randomly and equally into two groups. Each group was to perform tasks of deciding on the overall direction on urban renewal in Hong Kong, strategies for two neighborhood units (A and B) and some associated approaches.

In Section 1, group 1 participants were asked to use a traditional method to make decisions on the overall direction of urban renewal in Hong Kong, strategies for neighborhood A, and some associated approaches (Task 1). Similarly, group 2 also used a traditional method in Section 1. The only difference was that their focused neighborhood was B (Task 2). A general description of urban problems of Hong Kong, brief introductions to A and B, some associated spatial maps and statistical tables, were provided for participants. They were asked to complete the task within 20 minutes. During this process, they could freely surf the internet and search for different resources.

In section 2, the multi-scale model for decision-making was introduced to two groups. Group 1 was asked to decide on a general direction on urban renewal of Hong Kong and provide a strategy for neighborhood B (Task 2) by referring to results of the proposed model. The difference for Group 2 was that the neighborhood was changed to neighborhood A. The decision-making time was also 20 minutes, and what was allowed is the same as that in Session 1.

The design of the experimental study (see table 5) is to ensure effectiveness. First, every group can experience both a traditional method and application of the decision support model. Second, every group conducts the same task just once, thus not being influenced by a prior decision.

\section{- Please Insert Table 5 Here -}

\section{Questionnaire survey on participants}

There are mainly three parts in the questionnaire: (1) background information, (2) comparison on traditional method and the multi-scale model, and (3) open-ended questions on effectiveness of the model. The first part is to explore whether participants have relevant background and knowledge in urban planning, land use, urban renewal, and public participation. The second part aims at knowing whether the proposed model is more effective than the traditional method. The final part asks opinions of participants in terms of the satisfaction on the proposed model. Eighteen questionnaires were completed after two tasks. The results of the first part show that all participants are familiar with issues relating to urban planning, land use, and urban renewal whilst most of them have previous knowledge on focus group decision-making and public participation.

Table 6 shows the results from the second part, in which questions were asked about the extent of participants' agreement or disagreement with respect to several statements, by using a fourscale method (strongly agree, agree, disagree, and strongly disagree). Generally, participants agree that the proposed model can contribute to better decision-making on urban renewal compared with a traditional method. The standard deviation value for Question 8 is high 
because two participants disagree with the statement, which implies that the proposed model is more suitable for professionals' decision-making.

In the final part, one open-ended question asked the participants their favorite aspect of the proposed model. Comments were various. Most mentioned that the logic was clear and SA was particularly helpful. In terms of a question asking for participants' suggestions, some mentioned that the quality of data might be a concern.

Generally, the results from the experimental study illustrate that the proposed model and its sub-modules can benefit decision-making for urban renewal with objective and comprehensive decision-making references.

\section{- Please Insert Table 6 Here -}

\section{Discussion}

Unlike previous studies on urban renewal decision-making, this research focuses on multi-scale issues from both spatial and temporal dimensions. Firstly, the urban renewal system in a city is explored through the SD sub-module, which provides a direction for renewal. In an urban renewal system, social, economic, and environmental variables must be included. Special consideration should also be given to urban renewal characteristics in a local context. Secondly, LUS at district scale could identify possible land use problems and predict future alternatives under different scenarios. Thirdly, SA at a neighborhood scale assessed the current condition of a neighborhood from the dimensions of sustainability and building condition. By comparing two dimensions in a decision matrix, relevant strategies were obtained. Additionally, referring to calculation details in the process, specific issues for a neighborhood were identified. Through the combination of three sub-modules, comprehensive references for decision-making were provided, which involve both current and future issues, consider spatial and non-spatial data, as well as adopt a multi-scale perspective. Different modeling approaches and technical tools were used for developing sub-modules, which provided a positive example for collaborative decision-making.

Apart from technical validation in the sub-modules, the experimental study and expert interview validated the effectiveness of the proposed model from the perspective of human beings. Feedback from these two validation methods indicates that this multi-scale model can facilitate urban renewal decision-making with its more objective and informative results, compared with traditional methods.

This multi-scale model acts as a prototype for developing an integrated decision support system. Because three sub-modules were developed in different software, the integration of three submodules in one interface or software in the future may be a potential research area. More cases could be conducted for further application and validation. Another research direction is adding project scale into the model, with some projects having to be initiated from a single building. Sometimes, a single building redevelopment may lead to pencil development. The proposed 
multi-scale model addresses issues that might be met by a single project (e.g. financing).

\section{Conclusions}

Urban renewal process is beset with complexity, involving various issues, players, solutions and scales, all of which add difficulty and uncertainty to urban renewal decision-making. Although a considerable amount of research has been conducted to explore improving urban renewal decision-making, research from a multi-scale perspective on decision-making support is still an untouched area. Hence, this paper fills this gap by proposing a multi-scale model to support strategic decision-making in urban renewal. This model consists of three sub-modules and a supporting database. The three sub-modules act at city, district, and neighborhood scales respectively. At city scale, the SD sub-module explores the urban renewal system and provides a general direction for main policy-making direction. At district scale, land use in the future is simulated in the LUS sub-module to explore possible land use problems and the effects of policies/strategies in a renewal district. At neighborhood scale, SA studies the current condition of a neighborhood from the perspective of sustainability, so that associated strategies can be proposed. From the validation results, it is discovered that these three sub-models work interactively to provide multi-dimensional references for better and more objective decisionmaking.

The proposed model is the first attempt from a multi-scale perspective. Compared with previous research, the database established for the model is also more comprehensive because it involves both spatial and temporal dimensions. This model not only focuses on current issues (through the SA sub-module), but also pays attention to future status (through SD and LUS sub-modules). From a practical perspective, the proposed model can provide comprehensive and multidimensional references for decision-makers. Even only one sub-module within the model can make a difference on decision support. Under other contexts, this model can also be adapted. Urban renewal needs to consider other aspects such as financial availability, compensation issues, and allocation. Thus, a crucial point is that this model only serves as a reference for decision-making, but does not act as a decision-making model. Future studies could be conducted on other cases to improve the proposed model.

\section{Acknowledgement}

The authors wish to express their sincere gratitude to the Hong Kong Polytechnic University (PolyU) for the funding support to the research projects on which this paper is based, and also to Research Institute for Sustainable Urban Development (RISUD) in PolyU for its support to this research. 


\section{References}

Boyko CT, Gaterell MR, Barber AR, et al. (2012) Benchmarking sustainability in cities: The role of indicators and future scenarios. Global Environmental Change 22: 245-254.

Brown J and Barber A. (2012) Social infrastructure and sustainable urban communities. Proceedings of the Institution of Civil Engineers-Engineering Sustainability. Thomas Telford Ltd, 99-110.

Burrage H. (2011) Green hubs, social inclusion and community engagement. Proceedings of the Institution of Civil Engineers-Municipal Engineer. Thomas Telford Ltd, 167-174.

Chan EH and Lee GK. (2008a) Critical factors for improving social sustainability of urban renewal projects. Social Indicators Research 85: 243-256.

Chan EH and Lee GK. (2008b) Contribution of urban design to economic sustainability of urban renewal projects in Hong Kong. Sustainable Development 16: 353-364.

Colantonio A, Dixon T, Ganser R, et al. (2009) Measuring Socially Sustainable Urban Regeneration in Europe.

Haran M, McGreal S, Adair A, et al. (2008) Unlisted property fund investment in urban renewal/regeneration property in the UK: The impact of investment style on decision making. Journal of Real Estate Portfolio Management 14: 185-194.

Hemphill L, Berry J and McGreal S. (2004a) An indicator-based approach to measuring sustainable urban regeneration performance: part 1, conceptual foundations and methodological framework. Urban studies 41: 725-755.

Hemphill L, McGreal S and Berry J. (2004b) An indicator-based approach to measuring sustainable urban regeneration performance: Part 2, empirical evaluation and case-study analysis. Urban studies 41: 757-772.

Ho DCW, Yau Y, Law CK, et al. (2012) Social sustainability in urban renewal: An assessment of community aspirations. Urbani izziv 23: 125.

Ho DCW, Yau Y, Poon SW, et al. (2011) Achieving sustainable urban renewal in Hong Kong: Strategy for dilapidation assessment of high rises. Journal of Urban Planning and Development 138: 153-165.

Kauko T. (2012) End in sight? On the (un) sustainability of property development in the Budapest region. International Journal of Strategic Property Management 16: 37-55.

Kleinhans R. (2004) Social implications of housing diversification in urban renewal: A review of recent literature. Journal of Housing and the Built Environment 19: 367-390.

Laprise M, Lufkin S and Rey E. (2015) An indicator system for the assessment of sustainability integrated into the project dynamics of regeneration of disused urban areas. Building and Environment 86: 29-38.

Larsen HG and Hansen AL. (2008) Gentrification—-gentle or traumatic? Urban renewal policies and socioeconomic transformations in Copenhagen. Urban studies 45: 2429-2448. 
Lee GK and Chan EH. (2008) Factors affecting urban renewal in high-density city: Case study of Hong Kong. Journal of Urban Planning and Development 134: 140-148.

Lee GK and Chan EH. (2010) Evaluation of the urban renewal projects in social dimensions. Property Management 28: 257-269.

Mayer IS, van Bueren EM, Bots P, et al. (2005) Collaborative decisionmaking for sustainable urban renewal projects: a simulation-gaming approach. Environment and Planning B: Planning and Design 32: 403-423.

Murgante B, Las Casas G and Danese M. (2012) Analyzing Neighbourhoods Suitable for Urban Renewal Programs with Autocorrelation Techniques: INTECH Open Access Publisher.

Musterd S and Ostendorf W. (2008) Integrated urban renewal in The Netherlands: a critical appraisal. Urban Research \& Practice 1: 78-92.

Nijkamp P, Van Der Burch M and Vindigni G. (2002) A comparative institutional evaluation of publicprivate partnerships in Dutch urban land-use and revitalisation projects. Urban studies 39: 1865-1880.

Peng Y, Lai Y, Li X, et al. (2015) An alternative model for measuring the sustainability of urban regeneration: the way forward. Journal of Cleaner Production 109: 76-83.

Pérez MGR and Rey E. (2013) A multi-criteria approach to compare urban renewal scenarios for an existing neighborhood. Case study in Lausanne (Switzerland). Building and Environment 65: $58-70$.

Ruming KJ. (2010) Developer typologies in urban renewal in Sydney: recognising the role of informal associations between developers and local government. Urban Policy and Research 28: 65-83.

Schaaf AH. (1969) Economic feasibility analysis for urban renewal housing rehabilitation. Journal of the American Institute of Planners 35: 399-404.

Van Bortel G and Elsinga M. (2007) A network perspective on the organization of social housing in the Netherlands: the case of urban renewal in The Hague. Housing, Theory and Society 24: 32-48.

Verburg PH, Soepboer W, Veldkamp A, et al. (2002) Modeling the spatial dynamics of regional land use: the CLUE-S model. Environmental management 30: 391-405.

Wang H, Shen Q and Tang B-s. (2014) GIS-Based Framework for Supporting Land Use Planning in Urban Renewal: Case Study in Hong Kong. Journal of Urban Planning and Development.

Wang H, Shen Q, Tang B-s, et al. (2013) An integrated approach to supporting land-use decisions in site redevelopment for urban renewal in Hong Kong. Habitat International 38: 70-80.

Williams K and Dair C. (2007) A framework for assessing the sustainability of brownfield developments. Journal of Environmental Planning and Management 50: 23-40.

Winston N. (2010) Regeneration for sustainable communities? Barriers to implementing sustainable housing in urban areas. Sustainable Development 18: 319-330.

Yau Y and Chan HL. (2008) To rehabilitate or redevelop? A study of the decision criteria for urban 
regeneration projects. Journal of Place Management and Development 1: 272-291.

Zheng HW, Shen GQ, Song Y, et al. (2016) Neighborhood sustainability in urban renewal: An assessment framework. Environment and Planning B: Planning and Design: 0265813516655547.

Zheng HW, Shen GQ and Wang H. (2014) A review of recent studies on sustainable urban renewal. Habitat International 41: 272-279.

Zheng HW, Shen GQ, Wang H, et al. (2015a) Simulating land use change in urban renewal areas: A case study in Hong Kong. Habitat International 46: 23-34.

Zheng W, Shen G, Wang H, et al. (2015b) Critical issues in spatial distribution of public housing estates and their implications on urban renewal in Hong Kong. Smart and Sustainable Built Environment 4: 172-187.

Zipp S. (2012) The roots and routes of urban renewal. Journal of Urban History: 0096144212467306. 


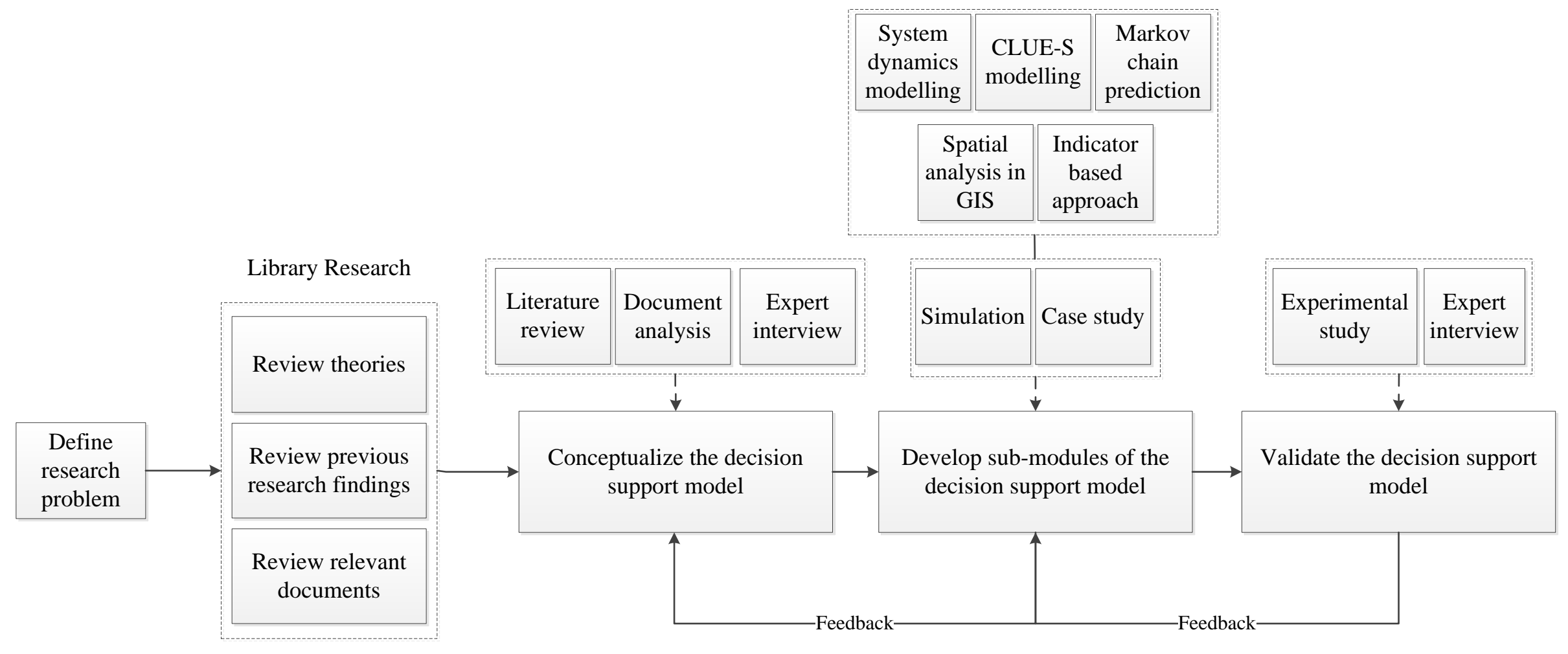

Figure 1 Research process in flow chart 


\section{Sub-module}

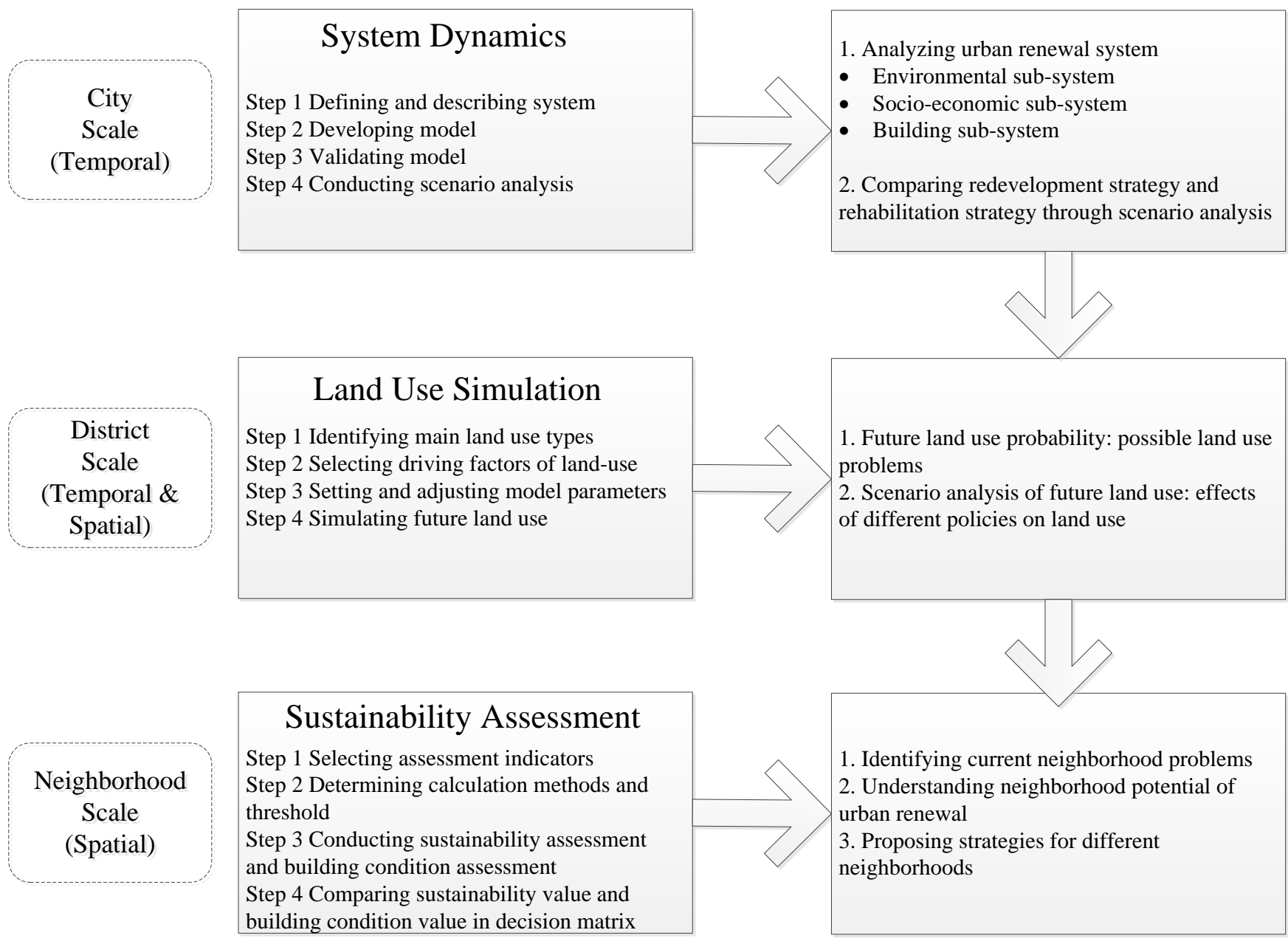

\section{Function}

General

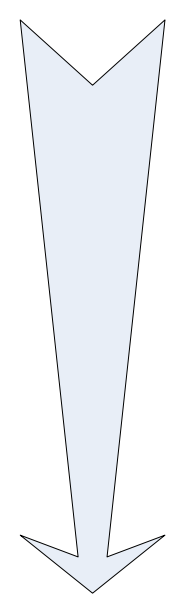

Specific

Figure 2 Development steps and functions of sub-modules 


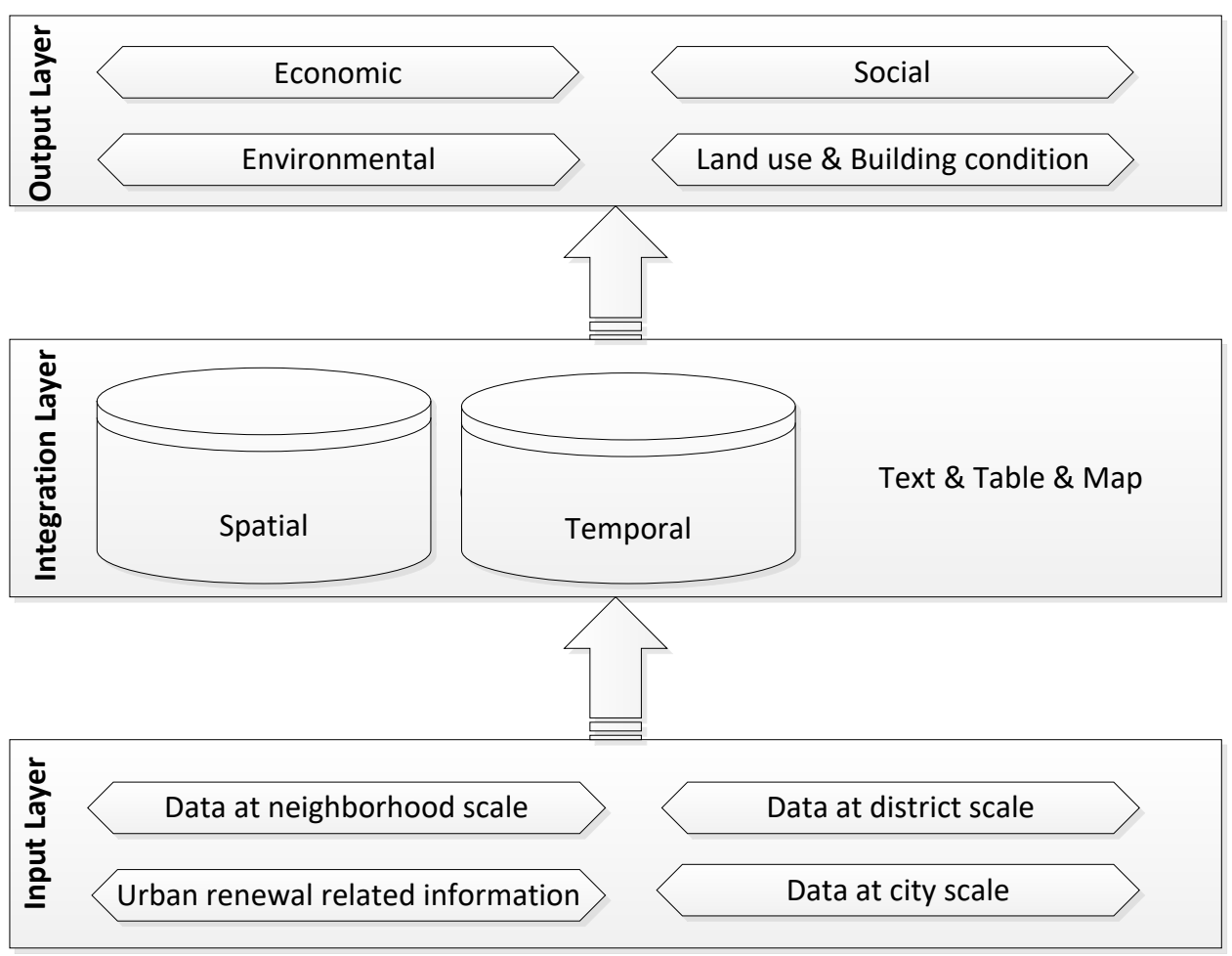

Figure 3 Supporting database 

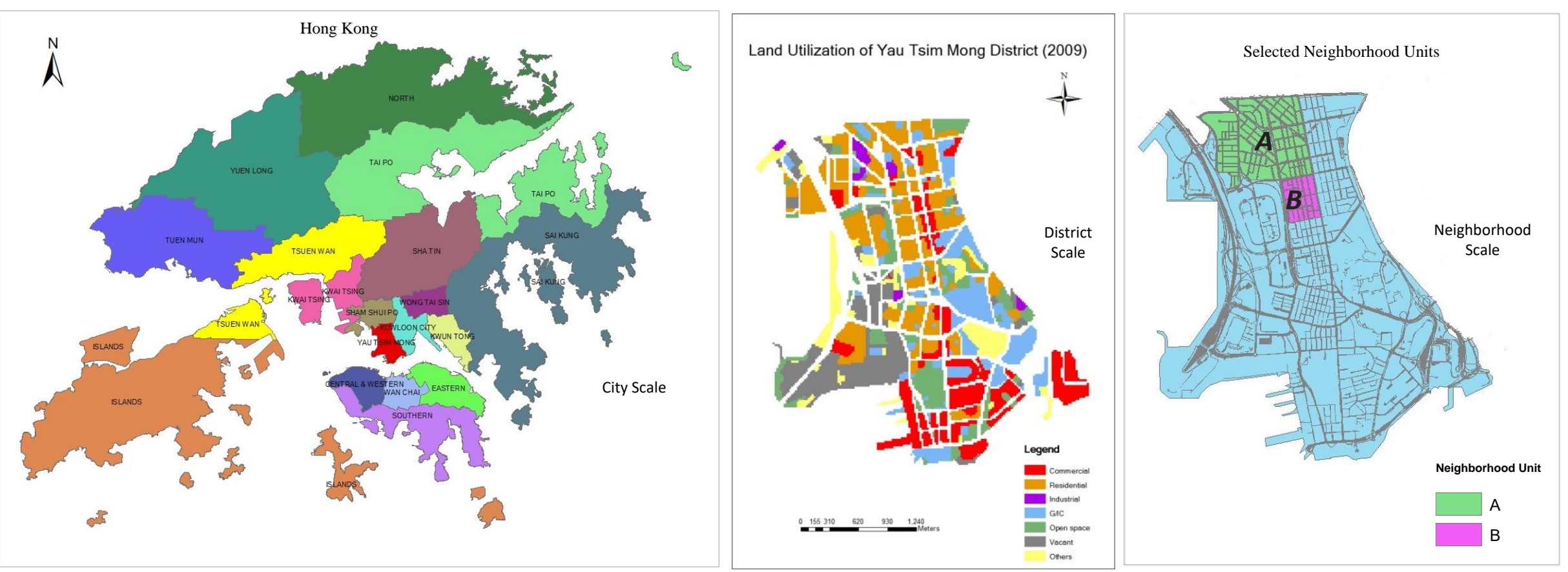

Figure 4 Case study area for developing sub-modules 


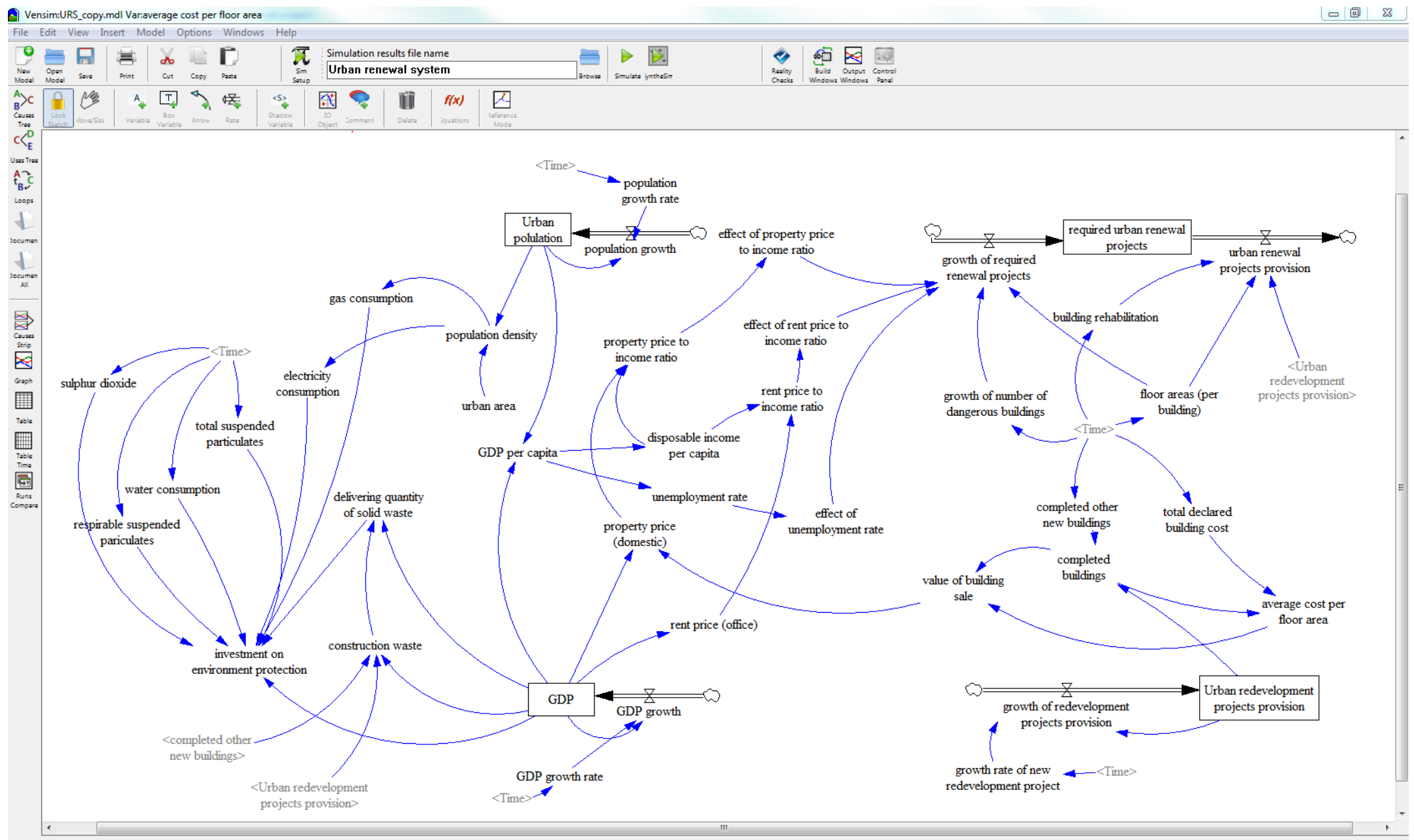

Figure 5 Modelling interface of SD development in Vensim 

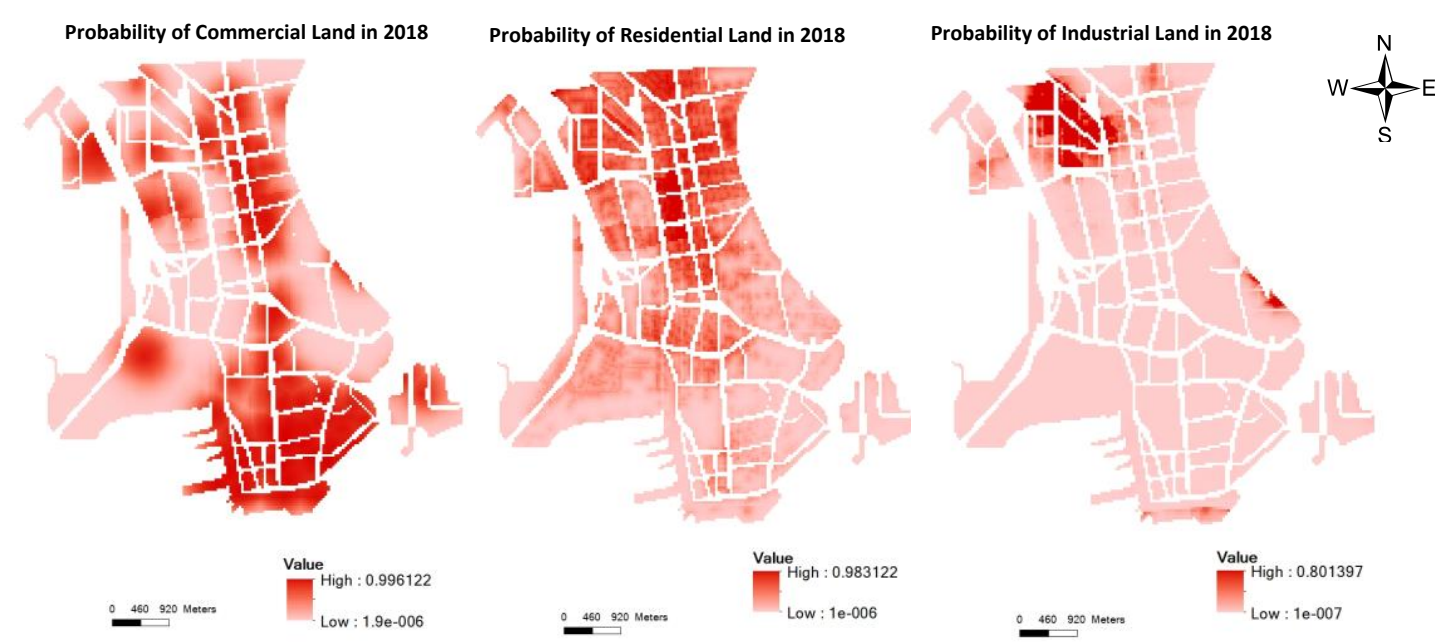

bability of Open Space in 2018

Probability of G/IC in 2018
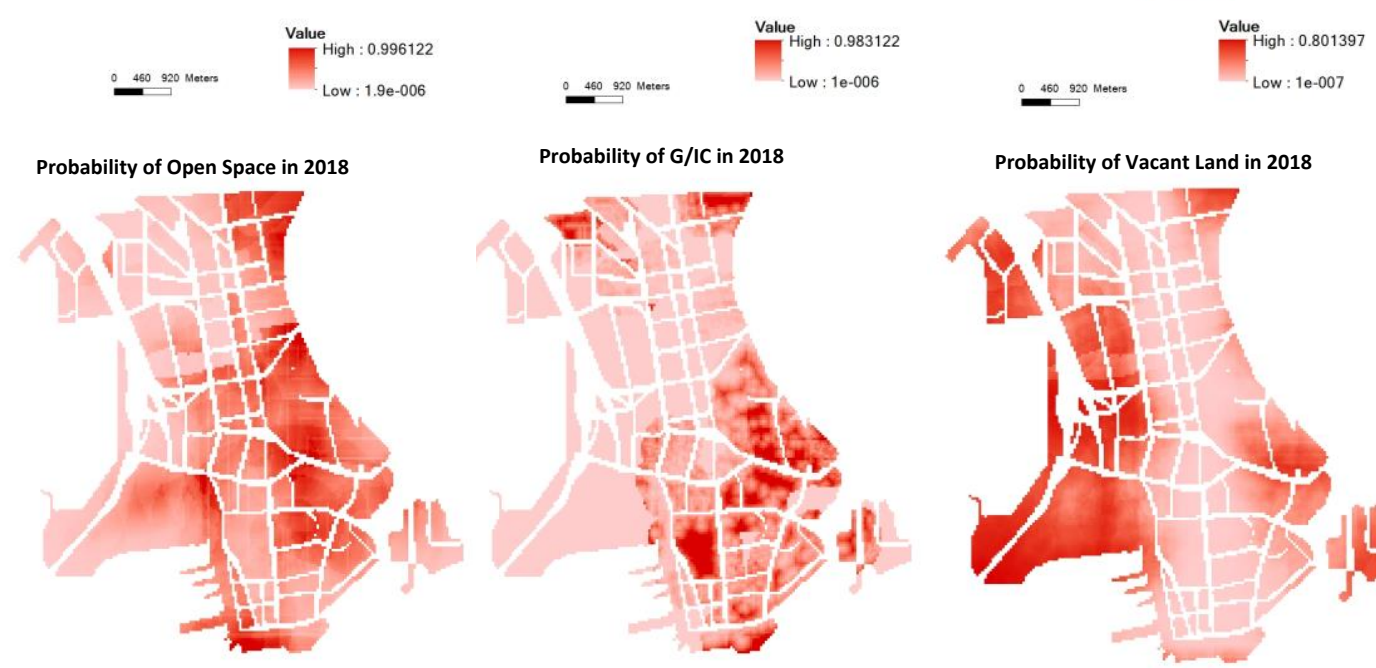

Probability of Vacant Land in 2018
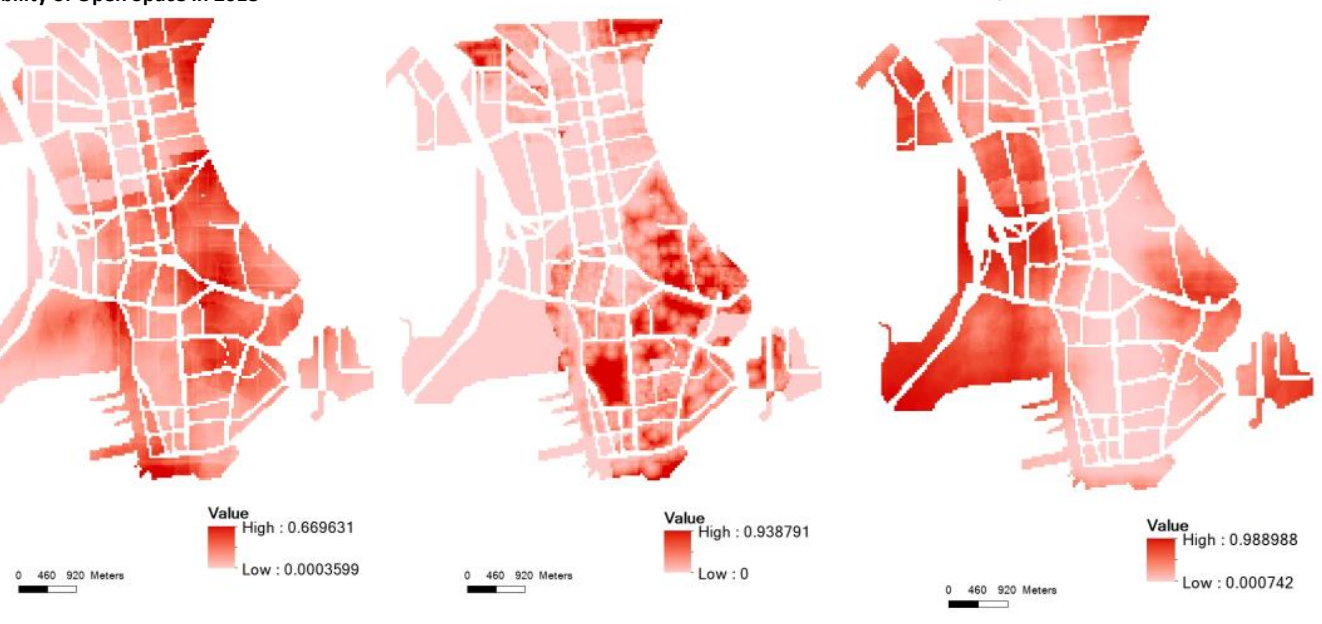

Figure 6 Probability maps of different land use types in 2018 
(Source: Zheng et al., 2015a)

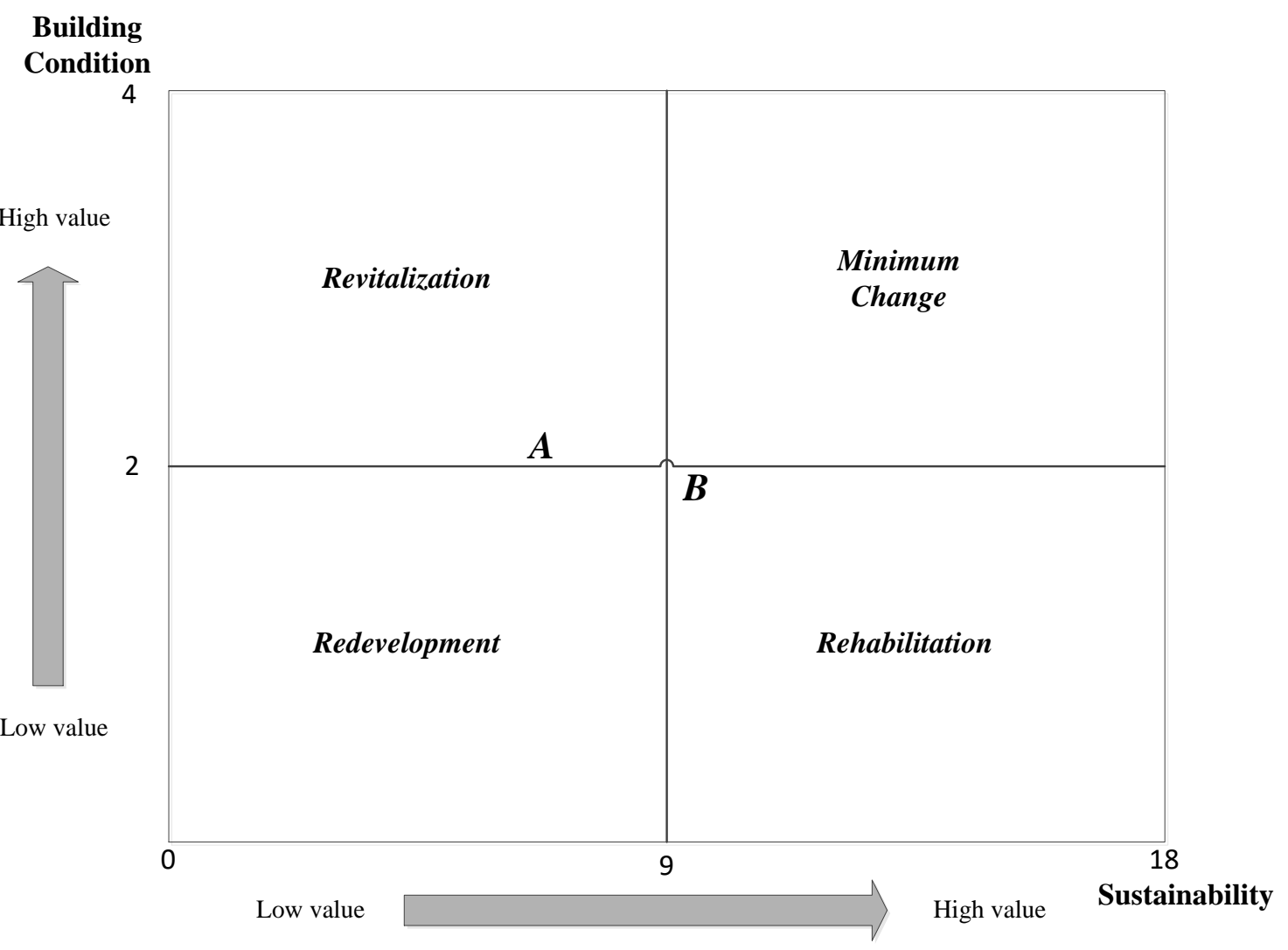

Figure 7 Urban renewal decision-making matrix 
Table 1 Simulation results of required urban renewal projects ( $\mathrm{m} 2$ gross floor area)

\begin{tabular}{llll}
\hline Time (Year) & $\begin{array}{l}\text { Scenario } 1 \\
\text { (baseline) }\end{array}$ & $\begin{array}{l}\text { Scenario } 2 \\
\text { (increasing provision of }\end{array}$ & $\begin{array}{l}\text { Scenario } 3 \\
\text { (increasing provision of } \\
\text { rehabilitation projects) }\end{array}$ \\
\hline $\mathbf{2 0 0 1}$ & $8.81 \mathrm{E}+07$ & $8.81 \mathrm{E}+07$ & $8.81 \mathrm{E}+07$ \\
$\mathbf{2 0 0 2}$ & $7.64 \mathrm{E}+07$ & $7.64 \mathrm{E}+07$ & $7.64 \mathrm{E}+07$ \\
$\mathbf{2 0 0 3}$ & $1.21 \mathrm{E}+08$ & $1.21 \mathrm{E}+08$ & $1.21 \mathrm{E}+08$ \\
$\mathbf{2 0 0 4}$ & $1.48 \mathrm{E}+08$ & $1.48 \mathrm{E}+08$ & $1.48 \mathrm{E}+08$ \\
$\mathbf{2 0 0 5}$ & $1.83 \mathrm{E}+08$ & $1.83 \mathrm{E}+08$ & $1.83 \mathrm{E}+08$ \\
$\mathbf{2 0 0 6}$ & $1.45 \mathrm{E}+08$ & $1.45 \mathrm{E}+08$ & $1.45 \mathrm{E}+08$ \\
$\mathbf{2 0 0 7}$ & $1.25 \mathrm{E}+08$ & $1.25 \mathrm{E}+08$ & $1.25 \mathrm{E}+08$ \\
$\mathbf{2 0 0 8}$ & $1.23 \mathrm{E}+08$ & $1.23 \mathrm{E}+08$ & $1.23 \mathrm{E}+08$ \\
$\mathbf{2 0 0 9}$ & $1.16 \mathrm{E}+08$ & $1.16 \mathrm{E}+08$ & $1.16 \mathrm{E}+08$ \\
$\mathbf{2 0 1 0}$ & $1.16 \mathrm{E}+08$ & $1.16 \mathrm{E}+08$ & $1.16 \mathrm{E}+08$ \\
$\mathbf{2 0 1 1}$ & $9.68 \mathrm{E}+07$ & $9.68 \mathrm{E}+07$ & $9.68 \mathrm{E}+07$ \\
$\mathbf{2 0 1 2}$ & $9.17 \mathrm{E}+07$ & $9.17 \mathrm{E}+07$ & $9.17 \mathrm{E}+07$ \\
$\mathbf{2 0 1 3}$ & $8.89 \mathrm{E}+07$ & $8.89 \mathrm{E}+07$ & $8.89 \mathrm{E}+07$ \\
& & & \\
& & &
\end{tabular}




\begin{tabular}{llll}
$\mathbf{2 0 1 4}$ & $8.26 \mathrm{E}+07$ & $8.26 \mathrm{E}+07$ & $7.62 \mathrm{E}+07$ \\
$\mathbf{2 0 1 5}$ & $7.63 \mathrm{E}+07$ & $7.63 \mathrm{E}+07$ & $6.36 \mathrm{E}+07$ \\
$\mathbf{2 0 1 6}$ & $7.00 \mathrm{E}+07$ & $6.99 \mathrm{E}+07$ & $5.09 \mathrm{E}+07$ \\
$\mathbf{2 0 1 7}$ & $6.36 \mathrm{E}+07$ & $6.35 \mathrm{E}+07$ & $3.81 \mathrm{E}+07$ \\
$\mathbf{2 0 1 8}$ & $5.72 \mathrm{E}+07$ & $5.69 \mathrm{E}+07$ & $2.53 \mathrm{E}+07$ \\
$\mathbf{2 0 1 9}$ & $5.07 \mathrm{E}+07$ & $5.00 \mathrm{E}+07$ & $1.25 \mathrm{E}+07$ \\
$\mathbf{2 0 2 0}$ & $4.42 \mathrm{E}+07$ & $4.27 \mathrm{E}+07$ & -449427 \\
$\mathbf{2 0 2 1}$ & $3.76 \mathrm{E}+07$ & $3.47 \mathrm{E}+07$ & $-1.34 \mathrm{E}+07$ \\
$\mathbf{2 0 2 2}$ & $3.08 \mathrm{E}+07$ & $2.55 \mathrm{E}+07$ & $-2.66 \mathrm{E}+07$ \\
$\mathbf{2 0 2 3}$ & $2.39 \mathrm{E}+07$ & $1.44 \mathrm{E}+07$ & $-3.98 \mathrm{E}+07$ \\
$\mathbf{2 0 2 4}$ & $1.69 \mathrm{E}+07$ & -146459 & $-5.33 \mathrm{E}+07$ \\
\hline
\end{tabular}

Table 2 Driving factors for different land use types (adapted from Zheng et al. (2015a))

\begin{tabular}{lccccccc}
\hline Driving Factors & Commercial & Residential & Industrial & G/IC & Open Space & Vacant & Others \\
\hline Slope & $\checkmark$ & $\checkmark$ & $\checkmark$ & & \\
\hline
\end{tabular}




\begin{tabular}{|c|c|c|c|c|c|c|c|}
\hline Elevation & $\checkmark$ & & $\checkmark$ & $\checkmark$ & $\checkmark$ & $\checkmark$ & $\checkmark$ \\
\hline Distance to CBD & $\checkmark$ & & & $\checkmark$ & & & $\checkmark$ \\
\hline $\begin{array}{l}\text { Distance to } \\
\text { airport }\end{array}$ & & & & & & & $\checkmark$ \\
\hline $\begin{array}{l}\text { Distance to MTR } \\
\text { stations }\end{array}$ & & $\checkmark$ & $\checkmark$ & & & $\checkmark$ & \\
\hline $\begin{array}{l}\text { Distance to bus } \\
\text { terminus }\end{array}$ & & & & $\checkmark$ & $\checkmark$ & $\checkmark$ & $\checkmark$ \\
\hline $\begin{array}{l}\text { Distance to } \\
\text { coastline }\end{array}$ & & & & $\checkmark$ & & & $\checkmark$ \\
\hline $\begin{array}{l}\text { Distance to } \\
\text { historic sites }\end{array}$ & & $\checkmark$ & $\checkmark$ & $\checkmark$ & & & $\checkmark$ \\
\hline $\begin{array}{l}\text { Distance to } \\
\text { schools }\end{array}$ & & $\checkmark$ & & & $\checkmark$ & & \\
\hline $\begin{array}{l}\text { Distance to open } \\
\text { space }\end{array}$ & & $\checkmark$ & $\checkmark$ & & $\checkmark$ & $\checkmark$ & \\
\hline Distance to road & & $\checkmark$ & $\checkmark$ & & $\checkmark$ & $\checkmark$ & \\
\hline
\end{tabular}




\begin{tabular}{llcl}
\hline $\begin{array}{l}\text { Distance to } \\
\text { hospital }\end{array}$ & $\checkmark$ & $\checkmark$ & $\checkmark$ \\
Population & $\checkmark$ & $\checkmark$ & $\checkmark$ \\
density & & & $\checkmark$ \\
Property price & & $\checkmark$ \\
\hline
\end{tabular}

Note: $\checkmark$ represents that the factor could explain land use change of that specific land use type.

Table 3 Indicators in SA

\begin{tabular}{lll}
\hline Dimension & Category & Indicator \\
\hline Sustainability & Social & Population density \\
\cline { 2 - 3 } & Social & Diversity of ages \\
\cline { 2 - 3 } & Social & Residential floor area per capita \\
\cline { 2 - 2 } & Social & Diversity of public transport \\
\cline { 2 - 2 } & Social & Diversity of public facilities \\
\cline { 2 - 2 } & Social & Conservation of built heritage resources \\
\hline Social & Accessibility to cultural facilities \\
\hline
\end{tabular}




\begin{tabular}{ll}
\hline Social & Accessibility to health care services \\
\hline Social & Accessibility to sport and leisure facilities \\
\hline Social & Accessibility to other facilities \\
\hline Social & Accessibility to public transport \\
\hline Economic & Labor force participation rate \\
\hline Economic & Disposable income per capita \\
\hline Economic & Diversity of business activities \\
\hline Economic & Density of Small businesses with local characteristics \\
\hline Environmental & Waste generation \\
\hline Environmental & Waste recycling \\
\hline Environmental & Electricity consumption \\
\hline Environmental & Air quality \\
\hline Environmental & Water consumption \\
\hline Environmental & Noise condition \\
\hline Environmental & Land use mix \\
\hline Building condition & Average building age \\
\hline
\end{tabular}




\begin{tabular}{ll}
\hline Building condition & Number of buildings aged above 50 years \\
\hline Building condition & Building repair \\
\hline Building condition & Building density \\
\hline Building condition & The fragment level of property rights \\
\hline
\end{tabular}

Table 4 Assessment scores of neighborhood units in SA

\begin{tabular}{lll}
\hline Neighborhood Unit & Sustainability & Building Condition \\
\hline A & 6.79 & 2.01 \\
\hline B & 9.52 & 1.99 \\
\hline
\end{tabular}

Table 5 Design of experimental study

\begin{tabular}{llll}
\hline & Method & Group 1 & Group 2 \\
\hline Section 1 & Traditional method & Task A & Task B \\
\hline
\end{tabular}




\section{Section 2}

With the help of the model results

Task B

Task A

Table 6 Results of part two in the questionnaire survey

\begin{tabular}{|c|c|c|}
\hline Questions & Mean & Standard deviation \\
\hline Q5. The proposed model makes me have a better understanding of the case study sites & 3.67 & 0.47 \\
\hline $\begin{array}{l}\text { Q6. The proposed model provides me with more useful information for decision-making of urban } \\
\text { renewal }\end{array}$ & 3.78 & 0.42 \\
\hline Q7. The proposed model enables me to better make decisions during the decision process & 3.50 & 0.50 \\
\hline $\begin{array}{l}\text { Q8. The information provided by the proposed model is easy to understand even for non- } \\
\text { professionals to express their opinions during the public participation process }\end{array}$ & 3.11 & 0.99 \\
\hline $\begin{array}{l}\text { Q9. The probability maps provided by land use change simulation can reveal some problems } \\
\text { relating to land use }\end{array}$ & 3.33 & 0.47 \\
\hline $\begin{array}{l}\text { Q10. The sustainability assessment enables me to better understand specific conditions of each } \\
\text { neighborhood }\end{array}$ & 3.44 & 0.60 \\
\hline Q11. The sustainability matrix is useful for me to make better decisions & 3.50 & 0.50 \\
\hline
\end{tabular}

Note: 4: strongly agree, 3 : agree, 2: disagree, 1: strongly diagree. 